\title{
Whey beverage improves hydrating capacity of the soccer players
}

\author{
${ }^{1}$ Hernández Miranda, J., ${ }^{1, *}$ Soto Simental, S., ${ }^{1}$ Güemes Vera, N., ${ }^{1}$ Piloni Martini, J., \\ ${ }^{1}$ Quintero Lira, A. and ${ }^{2}$ Rodríguez Ávila, J.A. \\ ${ }^{1}$ Instituto de Ciencias Agropecuarias. Universidad Autónoma del Estado de Hidalgo. Ave Universidad s/n \\ km 1. Ex Hacienda de Aquetzalpa. CP. 43600. Tulancingo, Hidalgo, México. \\ ${ }^{2}$ Instituto de Ciencias Básicas e Ingeniería. Universidad Autónoma del Estado de Hidalgo. Carretera \\ Pachuca-Tulancingo km 4.5. CP. 42183. Mineral de la Reforma, Hidalgo, México.
}

\author{
Article history: \\ Received: 29 January 2021 \\ Received in revised form: 25 \\ February 2021 \\ Accepted: 13 April 2021 \\ Available Online: 10 \\ September 2021
}

Keywords:

Whey beverage,

Hydration capacity,

Soccer player

DOI:

https://doi.org/10.26656/fr.2017.5(5).070

\begin{abstract}
The hydration process is critical in soccer players. The hydrating capacity, energy recovery, and electrolyte excretion in urine were determined by the use of a whey beverage as a hydration medium for high-performance athletes compared to the effects of purified water and a sport beverage. The study was carried out through an approved research protocol, which contemplates the determination of hydrating capacity by monitoring body weight during a period of exercise and a subsequent hydration period. Energy recovery was determined by monitoring blood glucose levels and electrolyte excretion was performed by quantifying the concentration of sodium $\left(\mathrm{Na}^{+}\right)$, potassium $\left(\mathrm{K}^{+}\right)$, calcium $\left(\mathrm{Ca}^{2+}\right)$ and magnesium $\left(\mathrm{Mg}^{2+}\right)$ in urine samples provided by the participants during the research protocol. It was concluded that the whey beverage has an appropriate capacity for hydration and energy recovery, while with regard to minerals it was observed that it effectively regulates the excretion of $\mathrm{Na}^{+}, \mathrm{Ca}^{2+}$ and $\mathrm{Mg}^{2+}$.
\end{abstract}

\section{Introduction}

The whey is a cheese industry by-product, it is obtained from the coagulation of milk casein (Broyard and Gaucheron, 2015; Chandrapala et al., 2015) and is usually defined as the liquid portion that is separated from milk when it is coagulated, lacking caseins and fat (Chandrapala et al., 2015). It is commonly categorized into two types: sweet and acid whey. The first type is produced from cheeses obtained by coagulation with rennet, while the second is obtained from cheeses made by acid precipitation adjusting $\mathrm{pH}$ to 4.6 (Broyard and Gaucheron, 2015) through the action of lactobacillus, adding organic acids (lactic acid) or hydrochloric acid or sulfuric acid (Nguyen et al., 2016; Ryan and Walsh, 2016; Risnar et al., 2019). Whey is the main component obtained by the cheese industry, its chemical composition comprises $93-94 \%$ of water (Risner et al., 2018) that contains approximately $55 \%$ of the solids present in whole milk. These include whey proteins, lactose, minerals such as calcium and phosphorus (Martins et al., 2018), water soluble vitamins for example vitamin $\mathrm{C}$, thiamine, riboflavin, pantothenic acid, pyridoxine and cobalamin (Chandrapala et al., 2015; Corrochano et al., 2018), organic acids such as lactic acid and citric acid, as well as non-protein nitrogenous compounds such as urea and uric acid (Monami et al., 2016). These components are modified depending on the type of whey, a consequence of the manufacturing process. Generally, sweet whey has a higher $\mathrm{pH}$, contains more protein and lactose, less fat and fewer minerals compared to acid whey. This byproduct's characteristics mean that it could potentially be used in the production of hydrating beverages. These types of drinks aim to regulate the body's hydration levels, the concentration of glucose in the blood and replace the electrolytes lost in sweating (Rodrigues et al., 2020), meaning that the nutritional characteristics of whey could play an important role in these processes. The components of this by-product could present a suitable hydration capacity for the human due to its high percentage of water, as well as its energy and mineral content.

The water balance in the body is maintained by dietary and it is important during sport and physical activity (Sekiguchi et al., 2019). The dehydration process is when the body loses water and there are changes in body mass, sweat rate and dehydration levels are influenced by environmental conditions, the intensity of 
exercise and clothes used (Yustika et al., 2019). Hydration assessment of physical activity is critical in soccer player and depend on several factors including body weight, thirst and urine concentration (Sekiguchi et al., 2020). However, there is little research about the properties of this by-product used to prepare hydration sports beverages. The objective of this study was to evaluate a beverage prepared with whey on hydration, energy recovery and excretion of main minerals involved in the hydration process.

\section{Materials and methods}

\subsection{Whey beverage elaboration}

Firstly, three different whey beverages were prepared prior to the development of a hydrating assay. Whey beverage formulation and chemical characteristics were showed in Table 1. Acidity was determined using phenolphthalein as an indicator according to AOAC (2019) and $\mathrm{pH}$ values were obtained using a $\mathrm{pH}$ meter Hanna model HI2211 (Hanna Instruments, CDMX, Mexico). Chemical analysis (protein, moisture, sugars, fat, lactose and ash) of the beverages were determined according to AOAC (2019) protocol numbers 927.05; 33.5.05; 991.20 and 2000.18.33.7.02. A refractometer Smart-1 (Atago, Washington, USA) was used to obtain the refraction index. Density was measured using a pycnometer method as indicated by Chatterjee et al.
(2015). Minerals were quantified using a Varian- 880 graphite furnace atomic absorption spectrometer (Agilent Technologies Canada Inc., Mississauga, Ontario, Canada). A total of $5 \mathrm{~g}$ of whey was dissolved into 50 $\mathrm{mL}$ of $3 \%$ nitric acid, then samples were used to determine sodium, potassium, calcium and magnesium as indicated by Rodrigues et al. (2020). To determine the safety of the beverage's aerobic mesophilic counts, staphylococcus, and moulds and yeast were determined as recommended by Mexican legislation (NOM-208SSA1-2011). After that, a sensory evaluation was conducted. Fresh samples of the beverages were used to make an acceptance test using seven points hedonic scale $(1=\mathrm{I}$ like it a lot and $7=\mathrm{I}$ dislike it a lot $)$. A total of 100 panellists were asked to perform the test. To each panellist was offered a $15 \mathrm{~mL}$ at $8^{\circ} \mathrm{C}$ of each formulation of the beverage. Samples were codified $(B 1=456$, B $2=$ 578 and $\mathrm{B} 3=132$ ).

\subsection{Clinical study}

This study was subjected to review and approval by the institutional Ethics and Research Committee (Protocol number CEEI-046-2019). The protocol is in accordance with the ethical standards established in the Declaration of Helsinki. Nine soccer players were randomly divided into three groups with three participants each. Each group was assigned a one of three-hydration beverage (control group A was hydrated

Table 1. Formulation of whey beverages

\begin{tabular}{|c|c|c|c|}
\hline \multirow{2}{*}{ Ingredients } & \multicolumn{3}{|c|}{ Formulation } \\
\hline & $\mathrm{B} 1$ & $\mathrm{~B} 2$ & B3 \\
\hline Whey, \% & 80 & 75 & 70 \\
\hline Orange juice, $\%$ & 19 & 24 & 29 \\
\hline Ginger juice, $\%$ & 1 & 1 & 1 \\
\hline \multicolumn{4}{|l|}{ Chemical composition } \\
\hline $\mathrm{pH}$ & $4.61 \pm 0.08^{\mathrm{a}}$ & $4.53 \pm 0.01^{\mathrm{a}}$ & $4.39 \pm 0.01^{\mathrm{b}}$ \\
\hline Acidity, $\mathrm{g} / \mathrm{L}$ expressed as lactic acid & $3.94 \pm 0.02^{\mathrm{a}}$ & $4.14 \pm 0.01^{b}$ & $5.02 \pm 0.01^{\mathrm{c}}$ \\
\hline Moisture, $\%$ & $93.32 \pm 1.19^{\mathrm{a}}$ & $94.30 \pm 1.01^{\mathrm{a}}$ & $94.60 \pm 1.14^{\mathrm{a}}$ \\
\hline Protein, \% & $0.81 \pm 0.02^{\mathrm{a}}$ & $0.76 \pm 0.04^{\mathrm{ab}}$ & $0.73 \pm 0.01^{\mathrm{b}}$ \\
\hline Fat, $\%$ & $0.48 \pm 0.02^{\mathrm{a}}$ & $0.46 \pm 0.01^{\mathrm{a}}$ & $0.39 \pm 0.01^{\mathrm{b}}$ \\
\hline Total sugars, $\mathrm{g} / \mathrm{L}$ & $3.55 \pm 0.015^{\mathrm{a}}$ & $3.64 \pm 0.005^{\mathrm{b}}$ & $3.77 \pm 0.01^{\mathrm{c}}$ \\
\hline Lactose, $\mathrm{g} / \mathrm{mL}$ & $0.054 \pm 0.0002^{\mathrm{a}}$ & $0.052 \pm 0.0001^{\mathrm{b}}$ & $0.045 \pm 0.0002^{\mathrm{c}}$ \\
\hline Ash, $\%$ & $0.69 \pm 0.01^{\mathrm{a}}$ & $0.63 \pm 0.01^{b}$ & $0.59 \pm 0.02^{b}$ \\
\hline Density, $\mathrm{g} / \mathrm{mL}$ & $1.054 \pm 0.0001^{\mathrm{a}}$ & $1.051 \pm 0.0001^{\mathrm{b}}$ & $1.046 \pm 0.002^{\mathrm{c}}$ \\
\hline Refraction index, oBx & $7.03 \pm 0.04^{\mathrm{a}}$ & $7.85 \pm 0.09^{b}$ & $8.16 \pm 0.04^{\mathrm{c}}$ \\
\hline Sodium, mg/L & $330.80 \pm 1.72^{\mathrm{a}}$ & $307.19 \pm 0.40^{\mathrm{b}}$ & $231.11 \pm 2.43^{\mathrm{c}}$ \\
\hline Potassium, mg/L & $3230.28 \pm 29.17^{\mathrm{a}}$ & $3204.21 \pm 47.60^{\mathrm{a}}$ & $2552.27 \pm 46.03^{b}$ \\
\hline Calcium, mg/L & $147.01 \pm 1.07^{\mathrm{a}}$ & $141.19 \pm 0.35^{b}$ & $116.36 \pm 0.85^{\mathrm{c}}$ \\
\hline Magnesium, mg/L & $343.20 \pm 2.4^{\mathrm{a}}$ & $333.18 \pm 1.01^{\mathrm{b}}$ & $251.24 \pm 0.44^{\mathrm{c}}$ \\
\hline Preference in sensorial analysis ${ }^{1}$ & $3.84 \pm 1.22^{\mathrm{b}}$ & $4.29 \pm 1.36^{\mathrm{a}}$ & $3.25 \pm 1.23^{\mathrm{c}}$ \\
\hline
\end{tabular}

${ }^{1} 7$-points hedonic scale $(1=\mathrm{I}$ like it a lot and $7=\mathrm{I}$ dislike it a lot. Values with the same lowercase superscript within the row are not significantly different $(\mathrm{p}>0.05)$ by Tukey test. 
with water; group B was hydrated with a whey beverage and group $\mathrm{C}$ was hydrated with a commercial sport beverage).

\subsection{Beverage characteristics}

Chemical composition and microbiological analysis of the hydration beverage used in the hydrating assay (Table 2).

\subsection{Selection of athletes}

Nine physically active men participated in this study who are members of a Soccer Training Centre in Tulancingo, Hidalgo, Mexico. These athletes carried out two-hour training sessions five times a week and followed a diet created by a nutritionist. The physical characteristics of these athletes were age $18.77 \pm 0.83$ years, height $172 \pm 0.03 \mathrm{~cm}$ and body weight $67.73 \pm 4.15$ $\mathrm{kg}$. The participants gave their written consent by means of an informed consent letter to participate in the project after being informed of the risks and procedures to which they would be subjected. The participants of each group underwent an athletic endurance test that consisted of jogging at a moderate exercise in a circuit for a period of sixty minutes while restricting liquids. The participants then rested for fifteen minutes for recovery and then hydrated with the corresponding hydrating medium at the end of this rest period (Li et al., 2015).

\subsection{Hydration assessment}

This was performed using gravimetry following the method described by Hailes et al. (2016) with some modifications, where the bodyweight of the participants was quantified with a Rhino ${ }^{\circledR}$ electronic scale - Baba180 model (Atizapan de Zaragoza, México) at the beginning of the athletic endurance test, prior to which the participants had emptied their bladders. Afterwards, the resistance test was carried out at the end of which the participants were again asked to carry out bladder emptying to quantify their body weight and thus determine the amount of weight lost. The participants were then hydrated according to their group, with the amount of liquid corresponding to $100 \%$ of the bodyweight loss during the test. After four hours, the participants emptied their bladder and then proceeded to take their body weight in order to determine the amount of water retained in the body.

\subsection{Energy recovery assessment}

The blood glucose measurement was performed with the use of a One touch ${ }^{\circledR}$ digital glucometer - Simple Select model (LifeScan Europe, Zug, Switzerland). A drop of blood obtained from a finger puncture at the beginning and end of the resistance test, as well as at the end of the hydration period, with the aim of knowing the initial blood glucose content, its behaviour at the end of physical activity and its concentration after hydration ( $\mathrm{Li}$ et al., 2015).

\subsection{Monitoring of urine electrolyte excretion}

Electrolyte excretion was determined following the method described by Jimenez-Pavón et al. (2015). In the urine samples provided by the participants, the amount of sodium, potassium, calcium and magnesium was quantified using a flame atomic absorption spectrophotometer (Varian, model SpectrAA 880, Mississuga, Canada) equipped with an air/acetylene flame burner head and hollow cathode lamp that was changed with each element detected. Ash was obtained from a $5 \mathrm{~g}$ urine sample which was diluted in $50 \mathrm{~mL}$ of a $3 \%$ solution of $\mathrm{NOH}_{3}$. The mineral concentration was determined by atomizing the solution and then burning it over a flame produced by a mix of acetylene and oxygen.

Table 2. Chemical composition of different beverage used in hydrating assay.

\begin{tabular}{lccc}
\hline \multirow{2}{*}{ Component } & \multicolumn{3}{c}{ Hydration medium } \\
\cline { 2 - 4 } & Water & Whey beverage Sport beverage \\
\hline Energy, kcal & 0 & 27 & 48 \\
Protein, \% & 0 & 1 & 0 \\
Moisture, \% & 99 & 94 & 98 \\
Sugars, \% & 0 & 4 & 12 \\
Fat, \% & 0 & 1 & 0 \\
Sodium, ppm & 6 & 236 & 2495 \\
Potassium, ppm & 5 & 828 & 281 \\
Calcium, ppm & 0 & 148 & 36 \\
Magnesium, ppm & 1 & 74 & 19 \\
Mesophilic bacteria count, Log CFU/mL & $1.19 \pm 0.056$ & $1.15 \pm 0.17$ & $1.21 \pm 0.04$ \\
Total coliforms, Log CFU/mL & $0.72 \pm 0.04$ & $0.75 \pm 0.04$ & $0.49 \pm 0.19$ \\
Moulds and yeast, Log CFU/mL & No growth & No growth & No growth \\
Staphylococcus, Log CFU/mL & No growth & No growth & No growth \\
pH & $4.56 \pm 0.05^{\text {b }}$ & $4.51 \pm 0.01^{\text {b }}$ & $4.38 \pm 0.01^{\text {a }}$ \\
\hline
\end{tabular}

Values with the same lowercase superscript within the row are not significantly different $(\mathrm{p}>0.05)$ by Tukey test. 
In order to obtain the urine samples, each participant was asked to provide the first urinary samples of the day (approximately $50 \mathrm{~mL}$ ). The participants then carried out the training protocol described at the end of the resistance test; they were asked to provide another urine sample. The participants were hydrated with their corresponding drink and rested for four hours, at the end of which the last urine sample was provided by the participants.

\subsection{Statistical analysis}

The data obtained for hydration was analysed using a linear model for samples repeated over time to determine the behaviour of the parameters relating to bodyweight, blood glucose and concentration of minerals in the urine samples provided during the test period. Afterwards, an ANOVA was performed to determine whether there were differences between weight loss and gain in hydration, initial and final glucose in the body, as well as initial and final mineral content in the urine $(\mathrm{p}<0.05)$. All analysis were performed with an IBM SPSS Statistics 20 statistical software.

\section{Results and discussion}

\subsection{Whey beverages}

The chemical characteristics of whey beverages are presented in Table 2. All measurements were different among beverages $(p<0.05)$ except moisture. Minerals as sodium, potassium, calcium and magnesium were higher in $\mathrm{B} 1$ formulation $(\mathrm{p}<0.05)$, this beverage has the highest content of whey. Buglass (2015) indicate that minerals included in isotonic beverage should be between 170 to $3750 \mathrm{mg} / \mathrm{L}$ for sodium, 0 to $450 \mathrm{mg} / \mathrm{L}$ for potassium, 0 to $420 \mathrm{mg} / \mathrm{L}$ for magnesium and 0 to $340 \mathrm{mg} / \mathrm{L}$ for calcium. According to the results, beverages elaborated in this study have the minerals suggested in isotonic beverage, except for potassium, however, World Health Organization (2012) recommend intake of $3510 \mathrm{mg} / \mathrm{d}$ to potassium and Epstein and Lifschitz (2016) suggest that a high potassium intake that includes glucose induces pancreatic insulin secretion and activates sodiumpotassium ATPase system to reduce postprandial potassium in the muscle cell. Water replenishment in athletes should be done by $0.7 \mathrm{~L}$ of isotonic solution with a concentration of $0.5-0.7 \mathrm{~g} / \mathrm{L}$ of sodium (Urdampilleta $e t$ al., 2013). Rodrigues et al. (2020) reported $60 \mathrm{mg} / \mathrm{L}$ for magnesium. Calcium content was lower than reported by Yasmin et al. (2015) and Rodrigues et al. (2020). However, it is important to highlight that bioavailability of this mineral in whey is high.

Results indicate that microbial load in whey beverages were similar among formulations $(p>0.05)$ and there no was growth of Staphylococcus, moulds and yeast. There no were differences among treatments in mesophilic bacteria counts $(\mathrm{P}>0.05)$ and the levels of them were low. These analyses demonstrate that this beverage is safe to drink for athletes. Tirtolini et al. (2019) prepared a sports beverage, using whey obtained from scotta, an end product of ricotta cheese, flavoured with citrus, they found higher levels of bacteriology analysis than found in this study, probably because ricotta cheese produces an acid whey during their production. However, Arranz et al. (2019) did not found bacteria or yeast in whey beverage added with marjoram extract in sealed UHT samples and slightly total bacteria counts in pasteurized samples.

Sensorial analysis of beverages indicates panellists prefer B2 formulation, indicating that this preference is due to a sweet flavour $(3.84,4.29$ and 3.25 for B1, B2 and B3, respectively). Chatterjee et al. (2015) indicate that consumers choose beverages added with orange juice $(40 \%)$ and sugar $(8 \%)$ because of the sweet flavour. Smith et al. (2016) reported that whey has sweet and cooked milk flavours, but these characteristics are modified by cheese production, milk thermal treatment, starters used, rennet method and milk pH.

\subsection{Hydration capacity}

The three groups that underwent the training protocol showed similar behaviour throughout the study (Table 2), where it was observed that from the initial weight of the participants, there was a loss at the end of the exercise period (60 mins). As a consequence of the elimination of water from the body through sweating, respiration and urine, a subsequent increase in body weight can be observed as hydration was administered to the participants, meaning that the weight recovered corresponds to the water retained in the body after the hydration period. Results indicate that there no was significant differences $(\mathrm{p}>0.05)$ among groups. However, athletes of the three groups lost the same amount of body weight ( $>0.05$ ) (Table 3 ), but weight gain after hydration did show significant differences $(\mathrm{p}<0.05)$, where $\mathrm{B}$ and $\mathrm{C}$ groups were similar and A group differed in the amount of weight gained. The differences in weight gain are the result of the beverage components, as when there are sugars and minerals such as sodium present in the hydration medium, a cotransport mechanism allows greater absorption of water through the intestine, generating greater recovery of liquid. In relation to this effect, Peake (2019) indicates that fluid retention is greater after ingesting liquids with $3-12 \%$ glucose. As treatment A lacks sugars and has a minimum amount of minerals, less water absorption was generated, unlike $\mathrm{B}$ and $\mathrm{C}$ which contain minerals and carbohydrates which could generate greater water absorption. This is consistent with the results as the whey 
beverage (treatment B) contains a higher content of $\mathrm{K}^{+}$, $\mathrm{Ca}^{2+}$ and $\mathrm{Mg}^{2+}$ which was possibly reflected in greater weight gain compared to Rodrigues et al. (2020) there were no significant differences between the athletes' initial and final weight during training when ingesting mineral water and an antioxidant beverage with peel extracts as a means of hydration. This could have been due to their mineral content influencing the co-transport of water in the body, generating weight gain.

Table 3. Bodyweight of the participants during training protocol

\begin{tabular}{cccc}
\hline \multirow{2}{*}{$\begin{array}{c}\text { Time } \\
\text { (minutes) }\end{array}$} & $\mathrm{4}$ & \multicolumn{3}{c}{ Treatments } \\
\cline { 2 - 4 } & \multicolumn{3}{c}{ Body weight $(\mathrm{Kg})$} \\
\hline 0 & $66.23 \pm 1.14$ & $66.5 \pm 2.84$ & $\mathrm{C}$ \\
\hline 60 & $65.28 \pm 1.04$ & $65.54 \pm 2.83$ & $66.65 \pm 1.50$ \\
300 & $65.96 \pm 1.00$ & $66.32 \pm 2.85$ & $67.43 \pm 1.64$ \\
\hline
\end{tabular}

A: Group hydrated with water $(\mathrm{n}=3)$, B: Group hydrated with whey beverage $(\mathrm{n}=3), \mathrm{C}$ : Group hydrated with sports beverage $(n=3)$.

\subsection{Energy recovery evaluation}

In order to assess energy recovery, the behaviour of blood glucose over time was studied. Table 4 shows similar behaviour for the three teams, where the amount of glucose increased between the start $(0 \mathrm{~min})$ and the end of the endurance test (60 mins). After hydration (300 mins) the amount of glucose decreased below the initial glucose level. According to the data obtained, there were no significant differences among the groups $(p>0.05)$ when analysing glucose variations over time. Furthermore, it was also observed that the treatments were shown to have had the same effect on the human organism, as there were no significant differences ( $p>0.05$ ) between the amount of blood glucose at the beginning of training and the amount present at the end of the hydration period (Table 4). The body has the ability to balance the amount of glucose in the blood by glycogenolysis and glycogenesis (Laurenson and Dubé, 2015), as after training there is an increase in the energy required before physical activity. After the hydration period, the liver stores glucose evening out its concentration in the blood. In addition, the presence of an exogenous contribution of carbohydrates, such as the whey beverage and sports beverage, generates a more effective glucose levelling. Regarding glucose recovery, the whey beverage had the effect of evening out the amount of glucose in the blood without showing any significant differences, although there was a slight difference between the initial and final glucose levels (Table 5). This may be due to the presence of carbohydrates in the hydration medium as mentioned by Schleh and Dumke (2018) who compare the use of an oral rehydration drink with a sports beverage, finding significant differences in blood glucose content, improving the athletes' performance, which can be attributed to the presence of sodium and sugars that, when combined, are transported by enzymes such as glucose transporters 1, 4 and 5. Similarly, Laurenson and Dubé (2015) observed an increase in glucose levels in athletes who consumed a drink that contains carbohydrates and proteins without affecting the respiratory exchange rate, suggesting that the presence of minerals, sugars and proteins as in the case of whey beverages facilitates blood glucose levelling.

Despite the fact that there are no significant differences between the different groups regarding the initial and final glucose content (Table 4), it can be seen that the greatest difference is found in the A group. This is a consequence of the use of water as a moisturizer as it does not generate an exogenous contribution of carbohydrates. It has also been reported that an intake of 0.3-0.8 $\mathrm{g}$ of protein per $\mathrm{Kg}$ of bodyweight with $0.5-0.8 \mathrm{~g}$ of carbohydrates per kg.hr-1 improves the resynthesis of muscle and liver glycogen after training. This in turn facilitates the stabilization of blood glucose levels, which seems to be due to its ability to increase glycogen synthase activity (Jäger et al., 2017; Peake, 2019). It is, therefore, possible that the whey beverage was the means of hydration that led to less variation in the results and presented an enhanced ability to level the blood glucose content, unlike water and sports beverages. In addition to this, the whey protein contains a higher branched-chain amino acid content such as leucine, which has an enhanced capacity to increase the insulin response by stimulating cellular glucose consumption (Laurenson and Dubé, 2015). Furthermore, studies have shown that the synchronization of aerobic and anaerobic exercises with whey proteins provides greater activation of the molecular signalling pathways that regulate the synthesis of molecular and fibrillar proteins as well as the synthesis of glycogen generating its replacement (Jäger et al., 2017), thereby favouring athletes who were hydrated with this medium.

Table 4. Loss and gain of body weight during hydration protocol

\begin{tabular}{cccc}
\hline \multirow{2}{*}{ Bodyweight } & \multicolumn{3}{c}{ Treatment } \\
\cline { 2 - 4 } & $\mathrm{A}$ & $\mathrm{B}$ & $\mathrm{C}$ \\
\hline Loss $(\mathrm{Kg})$ & $0.96 \pm 0.15^{\mathrm{a}}$ & $0.98 \pm 0.14^{\mathrm{a}}$ & $0.97 \pm 0.16^{\mathrm{a}}$ \\
Gain $(\mathrm{Kg})$ & $0.67 \pm 0.09^{\mathrm{a}}$ & $0.84 \pm 0.07^{\mathrm{b}}$ & $0.79 \pm 0.04^{\mathrm{b}}$ \\
\hline
\end{tabular}

A: Group hydrated with water $(n=3)$, B: Group hydrated with whey beverage $(n=3), C$ : Group hydrated with sports beverage $(n=3)$. Values are presented as mean \pm SD. Values with the same superscript within the row are not significantly different $(\mathrm{p}>0.05)$. 
Table 5. Glucose levels during hydration protocol

\begin{tabular}{|c|c|c|c|}
\hline \multirow{3}{*}{$\begin{array}{c}\text { Time } \\
\text { (minutes) }\end{array}$} & \multicolumn{3}{|c|}{ Treatments } \\
\hline & $\mathrm{A}$ & $\mathrm{B}$ & $\mathrm{C}$ \\
\hline & \multicolumn{3}{|c|}{ Blood glucose levels $(\mathrm{mg} / \mathrm{dL})$} \\
\hline 0 & $86.55 \pm 10.74^{\mathrm{Aa}}$ & $87.44 \pm 14.35^{\mathrm{Aa}}$ & $92.33 \pm 6.88^{\mathrm{Aa}}$ \\
\hline 60 & $95.77 \pm 14.99^{\mathrm{Aa}}$ & $95.55 \pm 8.45^{\text {Аa }}$ & $107.16 \pm 15.22^{\mathrm{Aa}}$ \\
\hline 300 & $78.33 \pm 23.91^{\mathrm{Aa}}$ & $84.55 \pm 9.24^{\mathrm{Aa}}$ & $86.50 \pm 7.55^{\mathrm{Aa}}$ \\
\hline
\end{tabular}

A: Group hydrated with water $(\mathrm{n}=3), \mathrm{B}$ : Group hydrated with the whey beverage $(n=3), C$ : Group hydrated with a sports beverage $(n=3)$. Values are presented as mean \pm SD. Values with the same uppercase superscript within the row are not significantly different $(\mathrm{p}>0.05)$ while values with the same lowercase superscript within the column are not significantly different $(\mathrm{p}>0.05)$.

\subsection{Monitoring of urine electrolyte excretion}

During high-intensity exercises or physical training, the human organism suffers significant hydroelectric losses that can require a period of recovery, for which water or isotonic consumption is generally recommended (Rodrigues et al., 2020). These losses can be related to sodium, potassium, calcium and magnesium content, which occur through sweating, urine and the excretion of faeces, while their concentration is also influenced by water loss in the organism through sweat and breathing. During the training protocol, it was observed that the three groups had a similar behaviour $(\mathrm{p}>0.05)$ regarding the concentration of $\mathrm{Na}^{+}$in urine (Figure 1a). Initial sodium excretion decreases after exercising for $60 \mathrm{mins}$ and later when performing hydration, excretion increased. Regarding water and whey beverages, however, the initial concentration was higher than the concentration after the hydration period, a behaviour that was not observed for the sports beverage as it generated an increase in the excretion of $\mathrm{Na}^{+}$after the hydration period greater than the initial excretion. This was due to the higher concentration of this electrolyte in the hydration medium, yet Hew-Butler et al. (2019) stated that further research is needed on mineral loss in urine. The amount of $\mathrm{K}^{+}$excretion showed an increase during the training protocol and the hydration period, and there were no significant differences $(p>0.05)$ between the teams (Figure 1b). This increase could be due to a higher ion content in plasma as hyperkaliaemic disorders have been mentioned when performing physically intense exercise (Hew-Butler et al., 2019). However, excretion through urine may depend on the physical activity performed, while the increase in potassium excretion after training can be justified by the decrease in $\mathrm{Na}^{+}$ excretion, as its reabsorption by the body stimulates $\mathrm{K}^{+}$ excretion. In the case of water as a hydration medium, no significant differences were found $(p>0.05)$ in the initial and final excretion of $\mathrm{K}^{+}$(Figure $1 \mathrm{~b}$ ). As a result of the participants having a high initial excretion and the hydration medium not containing high concentrations of $\mathrm{K}^{+}$, an increase in excretion after hydration did not occur. However, for the whey beverage and sport beverage, significant differences were observed $(p<0.05)$ because they both contain $\mathrm{K}^{+}$in their composition.

Regarding the mineral excretion in urine, the decrease in $\mathrm{Na}^{+}$excretion through the urine due to physical activity is produced by an increase in extrarenal and intrarenal sensors. These sensors secrete the antidiuretic hormone that regulates plasma volume by adjusting the excretion of sodium and water in the urine (Gonçalves et al., 2015), thereby avoiding excessive
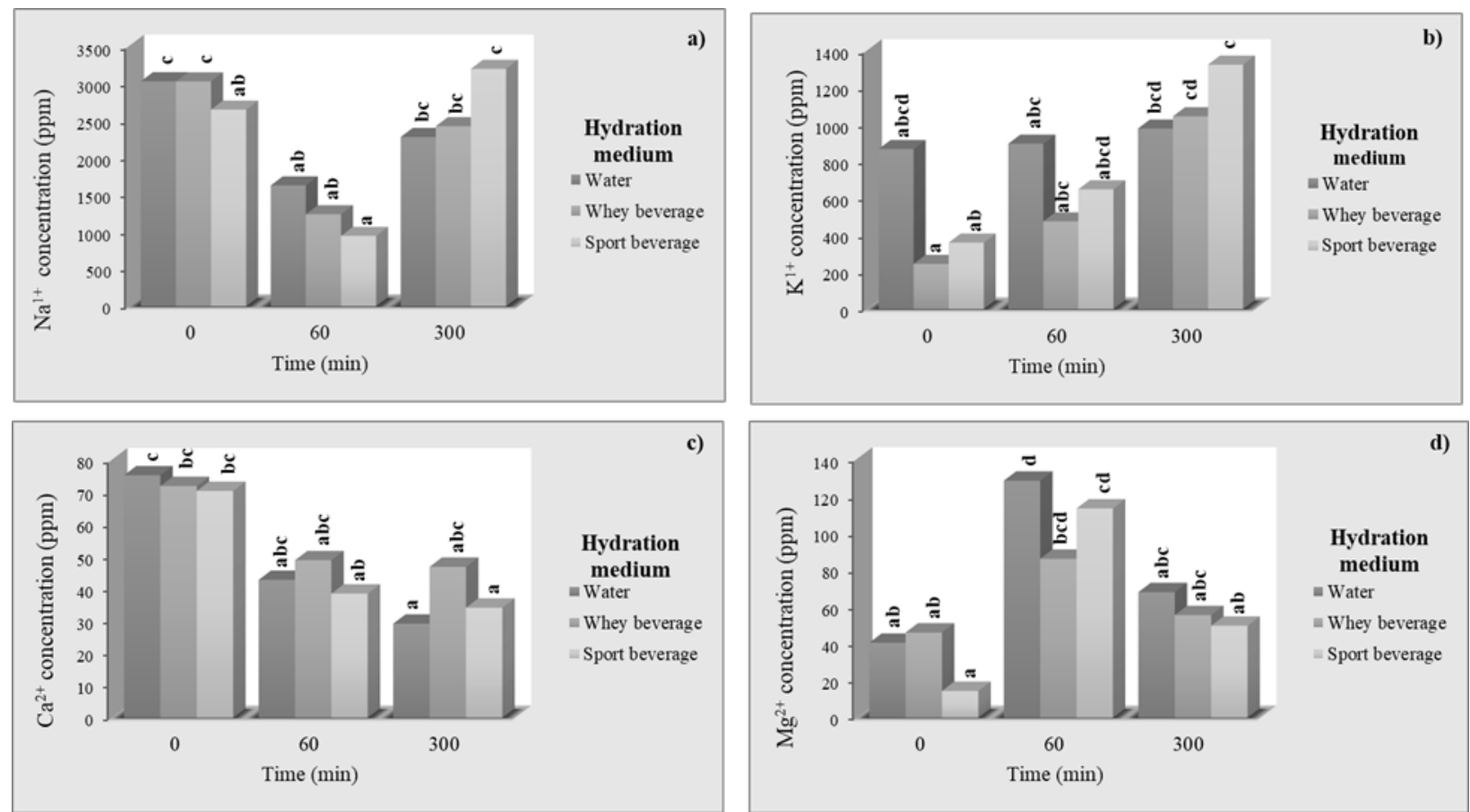

Figure 1. Excretion of minerals through urine during the research protocol where a) excretion of sodium, b) potassium, c) calcium and d) magnesium. Bars with different notations are significantly different between the treatments $(p<0.05)$. 
losses in the body. The subsequent increase is influenced by the regulation of $\mathrm{Na}^{+}$in the body through the administration of beverages, however, the increase in urine $\mathrm{Na}^{+}$excretion was observed after the hydration period in the case of water. This was due to the organism's homeostasis as a decrease in final excretion was observed compared to excretion after the athletic test. However, the increases observed for both parameters with the whey beverage and the sport beverage were influenced by the content of this electrolyte in the hydration medium. On the other hand, the use of the sports beverage showed significant differences $(p<0.05)$ between the initial and final sodium excretion (Figure 1), which was probably due to the higher concentration of this mineral. The initial excretion showed appropriate levels as reported by Gonçalves et al. (2015) whose reported excretion of $3645.5 \mathrm{ppm}$ in healthy young people. As can be seen, despite the fact that the whey beverage contained high concentrations of $\mathrm{K}^{+}$, the group that hydrated with the sports beverage excreted this mineral in higher concentrations in urine, which probably occurred because it contained a higher concentration of this mineral, which presented the ability to recover the $\mathrm{K}^{+}$lost in the organism with the excess excreted. In whey beverage that was expected to surpass the excretion levels of the group hydrated with the commercial drink. It is likely that the excess $\mathrm{K}^{+}$was eliminated from the organism through the faeces. Epstein and Lifschitz (2016) said that healthy people absorb practically all the $\mathrm{K}^{+}$ingested in the diet, but when a high amount enters the body or when kidney functions are compromised, this way is important to balance the body's homeostasis.

The concentration of $\mathrm{Ca}^{2+}$ presented similar behaviours to $\mathrm{Na}^{+}$, which decreased during the training protocol for the three groups without generating significant differences $(p>0.05)$. The values determined in the excretion of this electrolyte with the use of the different hydration medium were higher than those reported by Jiménez-Pavón et al. (2015). Although there were no significant differences among groups during the research protocol. However, differences $(p<0.05)$ were observed between the initial and final excretion of $\mathrm{Ca}^{2+}$ in urine (Figure 1c), where it was observed that the highest excretion was generated by the whey beverage due its high $\mathrm{Ca}^{2+}$ content.

The urine $\mathrm{Mg}^{2+}$ content increased at the end of training and decreased after the hydration period for the three teams without showing any significant differences $(p>0.05)$ between the groups (Figure 1d). The concentration at the beginning and end of the training periods did not show any significant differences $(p$ $<0.05$ ) for the treatments. However, a greater difference was observed for the sports beverage that increased the excretion of $\mathrm{Mg}^{2+}$ in urine in greater quantities (Figure 1d). Finally, despite an increase in $\mathrm{Mg}^{2+}$ excretion observed after the exercise period, (Muñoz et al., 2018) said that the magnesium ion concentration in plasma is reduced after exercise. This reduction is probably generated by the excretion of electrolytes in urine that increases its concentration as observed in Figure 1. On the other hand, in terms of the lower excretion levels at the beginning of the test and at the end of hydration, Muñoz et al. (2018) said that this elimination could be part of an adaptive process to avoid losses of this important element in the performance of athletes. In addition, the concentration of $\mathrm{Mg}^{2+}$ in urine is related to many factors such as diet, malnutrition, elimination processes and absorption, thyroid and parathyroid gland function, stress, excess aldosterone or metabolic disorders (Schuchardt and Hahn, 2017), all of which could possibly have influenced this result. However, the excretion of this electrolyte is close to the mean value of $65 \mathrm{ppm}$ reported for high-performance athletes (Muñoz et al., 2018), while it is possible that these results were influenced by the diet of the participants, the whey beverage generated greater final excretion that was similar to sports beverage usage.

\section{Conclusion}

The use of a whey beverage as a means of hydration presents suitable hydration capacity for the human body as it generated greater fluid retention compared to purified water and a sports beverage as a consequence of its nutritional composition. Furthermore, it presented an enhanced capacity to restore blood glucose levels as it was the means of hydration that kept initial and final glucose levels close, something which was probably due to the presence of sugars and whey proteins. Finally, this type of beverage did not show significant differences in the excretion of different electrolytes after hydration compared to a sports beverage. However, the concentration of $\mathrm{K}^{+}$requires further study. In addition, even though the whey beverage showed no significant difference with regard to $\mathrm{Na}^{+}$excretion, a higher concentration of this mineral is probably required in the whey beverage.

\section{Conflict of interest}

The authors declare no conflict of interest.

\section{Acknowledgments}

Hernández Miranda, J. received 928787 grant number from Consejo Nacional de Ciencia y Tecnología, Mexico. 


\section{References}

AOAC. (2019). Official Methods of Analysis of AOAC International. Method No. 927.05; 33.5.05; 991.20 and 2000.18.33.7.02. Gaithersburg, MD, USA: AOAC International.

Arranz, A., Corrochano, A.R., Shanahan, C., Villalva, M., Jaime, L., Santoyo, S., Callanan, M.J., Murphy, E. and Giblin, L. (2019). Antioxidant activity and characterization of whey protein-based beverages: Effect of shelf life and gastrointestinal transit on bioactivity. Innovative Food Science and Emerging Technology, 57, 102209. https://doi.org/10.1016/ j.ifset.2019.102209

Broyard, C. and Gaucheron, F. (2015). Modifications of structures and functions of caseins: a scientific and technological challenge. Dairy Science and Technology, 95, 831-862. https://doi.org/10.1007/ s13594-015-0220-y

Buglass, A.J. (2015). Chemical composition of beverages and drinks. In Cheung, P. and Mehta, B. (Eds.). Handbook of Food Chemistry, p. 225-300. Berlin, Heidelberg: Springer.

Chandrapala, J., Duke, M.C., Gray, S.R., Zisu, B., Weeks, M., Palmer, M. and Vasiljevic, T. (2015). Properties of acid whey as a function of $\mathrm{pH}$ and temperature. Journal of Dairy Science, 98(7), 43524363. https://doi.org/10.3168/jds.2015-9435

Chatterjee, G., De Neve, J., Dutta, A. and Das, S. (2015). Formulation and statistical evaluation of a ready-todrink whey based orange beverage and its storage stability. Revista Mexicana de Ingeniería Química, 14(2), 253-264.

Corrochano, A.R., Buckin, V., Kelly, P.M. and Giblin, L. (2018). Invited review: Whey proteins as antioxidants and promoters of cellular antioxidant pathways. Journal of Dairy Science, 101(6), 47474761. https://doi.org/10.3168/jds.2017-13618

Epstein, M. and Lifschitz, M.D. (2016). The Unappreciated Role of Extrarenal and Gut Sensors in Modulating Renal Potassium Handling: Implications for Diagnosis of Dyskalemias and Interpreting Clinical Trials. Kidney International Reports, 1(1), 43-56. https://doi.org/10.1016/j.ekir.2016.03.001

Gonçalves, C., Abreu, S., Padrão, P., Pinho, O., Graça, P., Breda, J., Santos, R. and Moreira, P. (2015). Association between sodium excretion and hydration status by Free Water Reserve: a cross-sectional analysis in adolescents. BMC Nutrition, 1, 17. https://doi.org/10.1186/s40795-015-0013-y

Hailes, W.S., Cuddy, J.S., Cochrane, K. and Ruby, B.C. (2016). Thermoregulation During Extended Exercise in the Heat: Comparisons of Fluid Volume and
Temperature. Wilderness and Environmental Medicine, 27(3), 386-392. https://doi.org/10.1016/ j.wem.2016.06.004

Hew-Butler, T., Smith-Hale, V.G. and Sabou, J. (2019). Exercise-associated electrolyte disorders. Current Opinion in Endocrine and Metabolic Research, 9, 51 -55. https://doi.org/10.1016/j.coemr.2019.06.014

Jäger, R., Kerksick, C.M., Campbell, B.I., Cribb, P.J., Wells, S.D., Skwiat, T.M., Purpura, M., Ziegenfuss, T.M., Ferrando, A.A., Arent, S.M., Smith-Ryan, A.E., Stout, J.P., Ormsbee, M.J., Taylor, L.W., Wilborn, C.D., Kalman, D.S, Kreider, R.B., Willoughby, D.S., Hoffman, J.R., Krzykowski, J.L. and Antonio, J. (2017). International Society of Sports Nutrition Position Stand: protein and exercise. Journal of the International Society of Sports Nutrition, 14, 20. https://doi.org/10.1186/s12970-017 $-0177-8$

Jiménez-Pavón, D., Cervantes-Borunda, M.S., Díaz, L.E., Marcos, A. and Castillo, M.J. (2015). Effects of a moderate intake of beer on markers of hydration after exercise in the heat: a crossover study. Journal of the International Society of Sports Nutrition, 12, 26. https://dx.doi.org/10.1186\%2Fs12970-015-00885

Laurenson, D.M. and Dubé, D.J. (2015). Effects of carbohydrate and protein supplementation during resistance exercise on respiratory exchange ratio, blood glucose, and performance. Journal of Clinical Translational Endocrinology, 2(1), 1-5. https:// doi.org/10.1016/j.jcte.2014.10.005

Li, L., Wong, S.H. and Sun, F.H. (2015). Effects of protein addition to carbohydrate-electrolyte solutions on postexercise rehydration. Journal of Exercise Science and Fitness, 13(1), 8-15. https:// doi.org/10.1016/j.jesf.2014.11.001

Martins, C.P.C., Ferreira, M.V.S., Esmerino, E.A., Moraes, J., Pimentel, T.C., Rocha, R.S., Freitas, M.Q., Santos, J.S., Ranadheera, C.S., Rosa, L.S., Teodoro, A.J., Mathias, S.P., Silva, M.C., Raices, R.S.L., Couto, S.R.M., Granato, S. and Cruz, A.G. (2018). Chemical, sensory, and functional properties of whey-based popsicles manufactured with watermelon juice concentrated at different temperatures. Food Chemistry, 255, 58-66. https:// doi.org/10.1016/j.foodchem.2018.02.044

Monami, D., Aryama, R. and Sadhan, K.G. (2016). Supply Chain of Bioethanol Production from Whey: A Review. Procedia Environmental Sciences, 35, 833-846. https://doi.org/10.1016/ j.proenv.2016.07.100

Muñoz, D., Llerena, F., Grijota, F.J., Robles, M.C., Alves, F.J. and Maynar, M. (2018). Influence of 
physical activity on urinary excretion of minerals and trace elements in subjects who live in the same geographic area. Revista Andaluza de Medicina del Deporte, 11(1), 7-11. https://doi.org/10.1016/ j.ramd.2016.07.003

Nguyen, D.N., Sangild, P.T., Li, Y., Bering, S.B. and Chatterton, D.E.W. (2016). Processing of whey modulates proliferative and immune functions in intestinal epithelial cells. Journal of Dairy Science, 99(2), 959-969. https://doi.org/10.3168/jds.20159965

Peake, J.M. (2019). Recovery after exercise: what is the current state of play? Current Opinion in Physiology, 10, 17-26. https://doi.org/10.1016/ j.cophys.2019.03.007

Risner, D., Shayevitz, A., Haapala, K., Meunier-Goddik, L. and Hughes, P. (2018). Fermentation and distillation of cheese whey: Carbon dioxideequivalent emissions and water use in the production of whey spirits and white whiskey. Journal of Dairy Science, 101(4), 2963-2973. https://doi.org/10.3168/ jds.2017-13774

Rodrigues, F.P., Bouzas, M.J.C., Licursi, O.L., Sena, B.D.S., Soares, J.D.T., Diniz, D.C. and Filomeno, F.E.A. (2020). Beverage based on whey permeate with phenolic extract of inimizea peel: A pilot study on effects on muscle and oxidative stress in trained individuals. Journal of Functional Foods, 65, 103749. DOI: 10.1016/j.jff.2019.103749.

Ryan, M.P. and Walsh, G. (2016). The biotechnological potential of whey. Reviews in Environmental Science and Biotechnology, 15, 479-498. https:// doi.org/10.1007/s11157-016-9402-1.

Schleh, M.W. and Dumke, C.L. (2018). Comparison of Sports Drink Versus Oral Rehydration Solution During Exercise in the Heat. Wilderness and Environmental Medicine, 29(2), 185-193. https:// doi.org/10.1016/j.wem.2018.01.005

Schuchardt, P. and Hahn, A. (2017). Intestinal Absorption and Factors Influencing Bioavailability of Magnesium- An Update. Current Nutrition and Food Science, 13(4), 260-278. https:// doi.org/10.2174/1573401313666170427162740

Sekiguchi, Y., Adams, W.M., Curtis, R.M., Benjamin, C.L. and Caja, D.J. (2019). Influencing hydration status during a National Collegiate Athletics Association division 1 soccer preseason. Journal of Science and Medicine Sport, 22(6), 624-628. https:// doi.org/10.1016/j.jsams.2018.12.005

Sekiguchi, Y., Kavouras, S.A., Yeargin, S.W., Ng, J.T.W. and Calabrese, P.S. (2020). Hydratation and heat strategies in soccer. In Curtis, R., Benjamin, C.,
Huggins, R. and Caja, D.J. (Eds). Elite Soccer Player: Maximizing Performance and Safety. New York: Taylor and Francis.

Tirtolini, E., Vasconi, M., Cattaneo, P., Moretti, V., Bellagamba, F., Bernardi, C. and Stella, S. (2020). A possible solution to minimize scotta as a food waste: A sports beverage. International Journal of Dairy Technology, 73(2), 421-428. https:// doi.org/10.1111/1471-0307.12647

Urdampilleta, A., Martínez-Sanz, J.M., Julia-Sanchez, S. and Álvarez-Herms, J. (2013). Protocolo de hidratación antes, durante y después de la actividad físico-deportiva. Motricidad. European Journal of Human Movement, 31, 57-76.

World Health Organization. (2012). Guidelines: Sodium intake for adults and children. Retrieved from WHO website: https://apps.who.int/iris/bitstream/ handle/10665/77985/9789241504836_eng.pdf

Yasmin, A., Butt, M.S., Yasin, M. and Qaisrani, T.B. (2015). Compositional analysis of developed whey based fructooligosaccharides supplemented lowcalorie drink. Journal of Food Science Technology, 52(3), 1849-1856. https://dx.doi.org/10.1007\% 2Fs13197-014-1535-Z

Yustika, G.P., Santoso, E.B. and Sumartiningsih, S. (2019). The importance of hydration for soccer athletes. Media Ilmu Keolahragaan Indonesia, 9(1), 23-31. https://journal.unnes.ac.id/nju/index.php/ miki/article/view/18427 